\title{
Prediction of Delayed Colonic Transit Using Bristol Stool Form and Stool Frequency in Eastern Constipated Patients: A Difference From the West
}

\author{
Veeravich Jaruvongvanich, ${ }^{1,2}$ Tanisa Patcharatrakul, ${ }^{2,3}$ and Sutep Gonlachanvit ${ }^{3 *}$ \\ ${ }^{\prime}$ Department of Internal Medicine, University of Hawaii, Honolulu, HI, USA; ${ }^{2}$ Department of Medicine, King Chulalongkorn Memorial Hospital, \\ Thai Red Cross Society, Bangkok, Thailand; and ${ }^{3}$ Gastrointestinal Motility Research Unit, Division of Gastroenterology, Department of Medicine, \\ Faculty of Medicine, Chulalongkorn University, Bangkok, Thailand
}

\begin{abstract}
Background/Aims
The correlation between the Bristol stool form scale (BSFS) and colonic transit time (CTT) has been reported in Western populations. Our study aims to study the relationship between BSFS, stool frequency, and CTT in Eastern patients with chronic constipation.

\section{Methods}

A total of 144 chronic functional constipation patients underwent colonic transit study by using radio-opaque markers, anorectal manometry, and balloon expulsion test. Stool diary including stool forms and frequency was recorded. Delayed CTT was defined as the retention of more than $20.0 \%$ of radio-opaque markers in the colon on day 5 .
\end{abstract}

\section{Results}

Twenty-five patients (17.4\%) had delayed colonic transit. Mean 5-day BSFS (OR, 0.51;95\% Cl, 0.34-0.79; $P=0.021)$ and stool frequency $(\mathrm{OR}, 0.60 ; 95 \% \mathrm{Cl}, 0.44-0.83 ; P=0.002)$ were independently associated with delayed $\mathrm{CTT}$ by logistic regression analysis. Mean 5-day BSFS (area under the curve [AUC], 0.73; 95\% Cl, 0.62-0.84; $P<0.001$ ) and stool frequency (AUC, $0.75 ; 95 \% \mathrm{Cl}, 0.63-$ $0.87 ; P<0.001$ ) fairly predicted delayed CTT. The optimal mean 5 -day BSFS of $\leq 3$ provided $68.0 \%$ sensitivity, $69.7 \%$ specificity, and $69.4 \%$ accuracy, and the optimal stool frequency $\leq 2$ bowel movements in 5 days provided $64.0 \%$ sensitivity, $83.1 \%$ specificity, and 84.0\% accuracy for predicting delayed CTT.

\section{Conclusions}

Both stool form and frequency were significantly associated with delayed CTT. Stool frequency $\leq 2$ and BSFS 1-3 rather than BSFS 1-2 that was used in the Westerners could be used as surrogate for delayed CTT in Eastern patients with constipation.

(J Neurogastroenterol Motil 2017;23:561-568)

\section{Key Words}

Bristol stool scale; Colonic motility; Colonic transit time; Constipation

Received: February 19, 2017 Revised: March 17, 2017 Accepted: April 2, 2017

() This is an Open Access article distributed under the terms of the Creative Commons Attribution Non-Commercial License (http://creativecommons. org/licenses/by-nc/4.0) which permits unrestricted non-commercial use, distribution, and reproduction in any medium, provided the original work is properly cited.

*Correspondence: Sutep Gonlachanvit, MD, MSc

Division of Gastroenterology, Department of Medicine, Faculty of Medicine, Chulalongkorn University, Pathumwan, Bangkok 10330, Thailand

Tel: +662-256-4265, Fax: +662-256-4504, E-mail: gsutep@hotmail.com 


\section{Introduction}

Chronic constipation is a common gastrointestinal disorder with the global prevalence of $12.0-17.0 \%$. ${ }^{1}$ The prevalence of constipation is different among geographic regions, which is lower in Southeast Asia (11.0\%) compared with Europe (16.0\%) and North America (14.0\%). ${ }^{1}$ Moreover, it accounts for one of the top 5 of gastrointestinal disorders in ambulatory clinics. ${ }^{2,3}$ Constipation not only significantly impairs patient's quality of life but also impacts on the economic burden, both direct health-care costs pronouncing 7500 US dollars per patient annually and indirect costs including loss of work productivity and work absence. ${ }^{4-6}$

In chronic idiopathic cases who do not respond to standard treatment, patients need further specialized investigations for assessing colonic and anorectal function to identify the underlying cause for the better view of optimal management. ${ }^{7}$ Biofeedback therapy has been found to improve bowel symptoms and anorectal function in constipated patients with dyssynergic defecation according to the American Neurogastroenterology and Motility Society and the European Society of Neurogastroenterology and Motility consensus. ${ }^{8}$ Those who have slow transit constipation might gain benefits from newer agents to restore colonic function, including serotoninergic enterokinetic agents, and intestinal secretagogues. Some of these patients might need more invasive approach including surgery (colectomy, ileostomy, or ileorectal anastomosis) or novel methods including neuromodulation therapy or sacral nerve stimulation. ${ }^{9-11}$ Various methods to assess colonic transit have been utilized including radio-opaque marker (ROM) studies, colonic transit scintigraphy, and wireless motility capsule studies. Of these, the colonic transit study using ROM seems to be the most widely performed due to its simplicity, inexpensiveness, and lack of the need of specialized equipment. Though most of the reported studies of colonic transit time (CTT) have been done in the West, a few studies from Asian showed different findings. Previous studies in the West showed mean normal CTT of 30-40 hours with the upper normal limit of 70 hours ${ }^{12-14}$ whereas studies in Asian healthy individuals showed faster transit times as the mean CTT of 15.8 hours in Indians, ${ }^{15}$ 16.8 hours in Koreans ${ }^{16}$ and 24.5 hours in Hong Kong people, respectively. ${ }^{17}$ This difference might be affected by race, ethnicity, and dietary habits. ${ }^{18}$

In clinical practice, clinicians usually treat patients with symptoms-based approach by using stool form and stool frequency to evaluate colonic transit. Bristol stool form scale (BSFS) was developed in 1970s by Lewis and Heaton with the aim to be a simple useful guide to standardize the stool forms and has been utilized in various clinical and research practices. ${ }^{19}$ However, BSFS demonstrated fair correlation with CTT in most studies. ${ }^{19-24}$ Two studies in healthy volunteers using laxative or antidiarrheal medications demonstrated that the longer CTT correlated with harder stools. ${ }^{19,22}$ Stool frequency also demonstrated mixed results on CTT correlation. $^{19-27}$

BSFS of 1 to 2 are considered as hard or lumpy stools and have been used for classification of irritable bowel syndrome (IBS) with constipation (IBS-C) subtype according to the Rome III criteria, whereas BSFS of 1 to 3 are classified as IBS-C for Asian patients based on the Asian Neurogastroenterology and Motility Association consensus. ${ }^{28,29}$ Asians demonstrated faster intestinal transit time in both healthy and IBS individuals compared with Westerners. ${ }^{29}$ However, the data on the association of stool form and CTT in Asians is limited and more validated information from the Asian population is needed.

The aim of this study is to explore the relationship between BSFS, stool frequency, and colonic transit study results in Eastern patients with chronic constipation.

\section{Materials and Methods}

\section{Patients}

During the period of May 2013 to December 2015, patients with chronic constipation who were not satisfied with laxatives and who visited the outpatient gastroenterology clinic at King Chulalongkorn Memorial Hospital, Bangkok, Thailand, were prospectively enrolled in this study. All patients had 2 or more following symptoms of more than 3 months: straining, lumpy or hard stools, sensation of incomplete evacuation, manual maneuver to facilitate defecation, sensation of anorectal obstruction or blockage or/and less than 3 bowel movements (BMs) a week. No rescue drugs were prescribed during the study period. Exclusion criteria were: (1) history of any gastrointestinal surgeries other than appendectomy, cholecystectomy, and cesarean section and (2) diagnosed as secondary constipation due to medication, anatomical disorders, and medical conditions, eg, hypothyroidism, diabetes mellitus, cerebrovascular disease, and hypercalcemia. All included patients underwent anorectal manometry, balloon expulsion test, and colonic transit study using solid ROMs. The techniques were described previously. ${ }^{30}$ Subjects were required to withhold any medications that effect gastrointestinal motility including laxatives, prokinetics, antidepressants, anxiolytics, and antipsychotics for 7 days prior to testing. 
Patients were then categorized as having defecation disorders if they have 2 of the following criteria during repeated attempts to defecate: (1) evidence of impaired evacuation based on balloon expulsion test and (2) inappropriate contraction of the pelvic floor or less than $20.0 \%$ relaxation of basal resting sphincter pressure or inadequate propulsive forces during attempted defecation by manometry. ${ }^{30}$ All patients completed a constipation symptom questionnaire which included straining, lumpy or hard stools, sensation of incomplete evacuation, manual maneuver to facilitate defecation, and sensation of anorectal obstruction/blockage.

Informed consent was obtained from all individual participants before enrolling in the study. This study was approved by the $\mathrm{Hu}$ man Research Ethic Committee of King Chulalongkorn Memorial Hospital.

\section{Assessment of Colonic Motility with Colonic Transit Study}

All subjects ingested 20 solid ROMs manufactured locally (diameter $5 \mathrm{Fr}$, length $1 \mathrm{~cm}$ each; Introducer sheath, Terumo, Japan) in 2 gelatin capsules, and the abdominal X-rays were obtained on day 1, 3, and 5 after ingestion. Subjects were on normal diet and normal activities during the study period. The weighted mean of ROM distribution in the (1) right colon, (2) left colon, (3) rectosigmoid colon, and (4) stool was expressed as a geometric center (GC, 1-4 respectively). The colon was divided into 3 parts defined by bony landmarks as described in a previous study. ${ }^{31}$ Delayed colonic transit was defined as the retention of more than $20.0 \%$ of ROMs (more than 4 ROMs) in the colon on day 5 after ingestion. ${ }^{32}$ The $\mathrm{X}$-rays were interpreted by 2 independent investigators without knowing the stool characteristics, subjects' profiles, and the date of imaging study.

\section{Assessment of Stool Form and Frequency}

After ingestion of ROMs, all participants were asked to record stool form of every BM in a stool diary during the 5-day study period. The stool form was graded using the BSFS ranging from 1 to 7. ${ }^{19}$ The lower score reflects the harder stool. Because the stool form is usually harder at the beginning and softer at the end of each BM, the BSFS was graded base on the hardest stool form at the beginning of each BM. The mean BSFS of all BMs during the 5-day study period was obtained from the stool diary. Stool frequency was expressed as a total number of BMs in 5 days.

\section{Statistical Methods}

All statistical analyses were performed by SPSS version 21.0 for Mac (SPSS Inc, Chicago, IL, USA). Data were presented as mean $\pm \mathrm{SD}$ or proportions (\%). Comparisons between 2 groups were performed by unpaired Student's $t$ test for continuous data and Chi-square test for nominal data. Relationship of stool form and frequency with GC was calculated using Spearman's correlation. The strength of correlation is interpreted as weak $(\rho=-0.3$ to -0.1 or 0.1 to 0.3 ), moderate ( $\rho=-0.5$ to -0.3 or 0.3 to 0.5 ), and strong ( $\rho=-1.0$ to -0.5 or 1.0 to 0.5 ), respectively. Receiver operating characteristic (ROC) analysis was performed to calculate the cut-off value, sensitivity, specificity, and accuracy for discriminating patients with delayed CTT from normal transit. An area under the curve (AUC) of more than 0.7, 0.8, and 0.9 were considered as fair, good, and excellent tests, respectively. The optimal cut-off value was determined when the point yields the best sensitivity and specificity in ROC curve. Multivariate logistic regression analysis was used to determine which factors were independently associated with delayed CTT. The $P$-value of less than 0.05 was considered as statistically significant.

\section{Results}

\section{Subject Characteristics}

This study cohort consisted of 144 patients with a mean age of $52.0 \pm 16.6$ years, and $70.8 \%$ were female. The prevalence of constipation symptoms was reported as followed: straining (84.0\%), hard stools $(65.3 \%)$, sensation of incomplete evacuation (81.9\%), manual maneuver to facilitate defecation $(45.1 \%)$, and sensation of anorectal blockage (70.1\%). Mean stool frequency was 4 (2.35.0) BMs per 5 days. The mean 5-day BSFS was $3.5 \pm 1.3$. Of all patients, 25 patients $(17.4 \%)$ had delayed CTT, 70 patients $(48.6 \%)$ had IBS symptoms, and 58 patients $(40.3 \%)$ had defecation disorder.

\section{Features Comparison Between Patients With Delayed Colonic Transit Time Versus Normal Colonic Transit Time}

There was no significant difference in age, gender, body mass index, prevalence of defecation disorder and IBS symptoms, and constipation symptoms including straining, hard stools, incomplete evacuation, manual maneuver to facilitate defecation, and sensation of anorectal blockage, between patients with and without delayed CTT. Delayed CTT patients presented with significantly fewer mean stool frequency $(2.5 \pm 2.0$ vs $4.3 \pm 1.9$ BMs per 5 days, $P$ $<0.001$ ), and harder stool form (mean 5-day BSFS of $2.6 \pm 1.4$ vs $3.7 \pm 1.3, P<0.001)$ compared to patients with normal CTT. 
Table 1. Baseline Characteristics Compared Between Patients With Delayed and Normal Colonic Transit Study

\begin{tabular}{|c|c|c|c|c|}
\hline & $\begin{array}{c}\text { Total } \\
(\mathrm{N}=144)\end{array}$ & $\begin{array}{c}\text { Delayed CTT } \\
\quad(\mathrm{n}=25)\end{array}$ & $\begin{array}{l}\text { Normal CTT } \\
\quad(\mathrm{n}=119)\end{array}$ & $P$-value \\
\hline Age (yr) & $52.0 \pm 16.6$ & $53.0 \pm 16.5$ & $51.8 \pm 16.7$ & 0.756 \\
\hline Sex (\% female) & $102(70.8)$ & $19(76.0)$ & $83(69.7)$ & 0.534 \\
\hline $\mathrm{BMI}\left(\mathrm{kg} / \mathrm{m}^{2}\right)$ & $22.8 \pm 3.7$ & $21.4 \pm 2.8$ & $23.1 \pm 3.8$ & 0.055 \\
\hline Defecation disorder (n [\%]) & $58(40.3)$ & $13(52)$ & $45(37.8)$ & 0.187 \\
\hline Fulfilled IBS criteria (n [\%]) & $70(48.6)$ & $12(48)$ & $58(48.7)$ & 0.946 \\
\hline \multicolumn{5}{|l|}{ Constipation symptoms (n [\%]) } \\
\hline Straining & $121(84.0)$ & $23(92.0)$ & $98(82.4)$ & 0.230 \\
\hline Hard stools & $94(65.3)$ & $19(76.0)$ & $75(63.0)$ & 0.222 \\
\hline Incomplete evacuation & $118(81.9)$ & $22(88.0)$ & $96(80.7)$ & 0.394 \\
\hline Manual maneuver to facilitate defecation & $65(45.1)$ & $12(48.0)$ & $53(44.5)$ & 0.746 \\
\hline Sensation of anorectal blockage & $101(70.1)$ & $20(80.0)$ & $81(68.1)$ & 0.228 \\
\hline \multicolumn{5}{|l|}{ Stool characteristics } \\
\hline Average 5-day BSFS & $3.5 \pm 1.3$ & $2.6 \pm 1.4$ & $3.7 \pm 1.3$ & $<0.001$ \\
\hline Stool frequency (BMs/5 days) & $4.0 \pm 2.0$ & $2.5 \pm 2.0$ & $4.3 \pm 1.9$ & $<0.001$ \\
\hline \multicolumn{5}{|l|}{ Geometric center } \\
\hline Day 1 & $2.5 \pm 0.9$ & $1.8 \pm 0.8$ & $2.6 \pm 0.9$ & $<0.001$ \\
\hline Day 3 & $3.5 \pm 0.7$ & $2.6 \pm 0.6$ & $3.7 \pm 0.5$ & $<0.001$ \\
\hline Day 5 & $3.8 \pm 0.4$ & $3.1 \pm 0.5$ & $4.0 \pm 0.02$ & $<0.001$ \\
\hline
\end{tabular}

CTT, colonic transit time; BMI, body mass index; IBS, irritable bowel syndrome; BSFS, Bristol stool form scale; BMs, bowel movements.

Data express as mean $\pm \mathrm{SD}$.

Table 2. Predictors of Delayed Colonic Transit Time by Using Multivariate Logistic Regression Analysis

\begin{tabular}{lccc}
\hline \multicolumn{1}{c}{ Variable } & Adjusted OR $^{\mathrm{a}}$ & $95 \% \mathrm{CI}$ & $P$-value \\
\hline Average 5-day BSFS & 0.51 & $0.34-0.79$ & 0.021 \\
Stool frequency (BMs/5 days) & 0.60 & $0.44-0.83$ & 0.002 \\
\hline
\end{tabular}

${ }^{a}$ Adjusted to age, sex, body mass index, and irritable bowel syndrome.

BSFS, Bristol stool form scale; BMs, bowel movements.

The GC was significantly more proximal in delayed CTT group compared with normal colonic transit group for day 1 (1.8 \pm 0.8 vs $2.6 \pm 0.9)$, day $3(2.6 \pm 0.6$ vs $3.7 \pm 0.5)$, and day 5 ( $3.1 \pm 0.5$ vs $4.0 \pm 0.02)$ (all $P$-values $<0.001)$. The main features of subjects are summarized in Table 1.

\section{Accuracy of Stool Form and Frequency for Predicting Delayed Colonic Transit Time}

Multivariate logistic regression analysis indicated that the mean 5-day BSFS (OR, 0.51; 95\% CI, 0.34-0.79; $P=0.020)$ and stool frequency (OR, $0.60 ; 95 \% \mathrm{CI}, 0.44-0.83 ; P=0.002)$ were independently associated with delayed CTT after adjusting for age, gender, and body mass index (Table 2).

The ROC analysis for predicting delayed CTT indicated that BSFS of the mean 5-day BSFS (AUC, 0.73; 95\% CI, 0.62-0.84; P
Table 3. Sensitivity, Specificity, and Accuracy of Mean 5-day Bristol Stool Form Scale and Stool Frequency in Diagnosing Delayed Colonic Transit Time

Sensitivity Specificity Accuracy

(\%) (\%)

\begin{tabular}{llll}
\hline Mean 5-day BSFS & & & \\
1 & 28.0 & 94.1 & 82.6 \\
1-2 & 40.0 & 84.9 & 77.1 \\
1-3 & 68.0 & 69.7 & 69.4 \\
1-4 & 96.0 & 37.0 & 47.2 \\
Stool frequency (BMs/5 days) & & & \\
0-1 & 32.0 & 95.0 & 84.0 \\
0-2 & 64.0 & 83.1 & 84.0 \\
$0-3$ & 68.0 & 66.4 & 66.7 \\
$0-4$ & 80.0 & 51.3 & 56.3 \\
\hline
\end{tabular}

BSFS, Bristol stool form scale; BMs, bowel movements.

$<0.001$ ), and stool frequency (AUC, $0.75 ; 95 \% \mathrm{CI}, 0.63-0.87 ; P$ $<0.001$ ) fairly predicted delayed CTT. The optimal value of mean 5-day BSFS for predicting delayed CTT was less than or equal to 3 providing $68.0 \%$ sensitivity, $69.7 \%$ specificity, $69.4 \%$ accuracy, $32.1 \%$ positive predictive value, and $91.2 \%$ negative predictive value. Optimal stool frequency was less than or equal to $2 \mathrm{BMs}$ per 5 days providing $64.0 \%$ sensitivity, $83.1 \%$ specificity, $84 \%$ accuracy, 
Table 4. Spearman's Correlation of Stool Characteristics and Constipation Symptoms With Geometric Center

\begin{tabular}{lccc}
\hline & GC day 1 & GC day 3 & GC day 5 \\
\hline Mean 5-day BSFS & $0.35^{\mathrm{a}}$ & $0.38^{\mathrm{a}}$ & $0.32^{\mathrm{a}}$ \\
Stool frequency (BMs/5 days) & $0.31^{\mathrm{a}}$ & $0.33^{\mathrm{a}}$ & $0.36^{\mathrm{a}}$ \\
Constipation symptoms & & & -1.21 \\
$\quad$ Straining & -0.57 & -0.13 & -0.71 \\
Hard stools & -1.51 & -0.05 & 0.005 \\
Incomplete evacuation & -0.03 & 0.08 & -0.06 \\
Manual maneuver to facilitate defecation & 0.002 & 0.04 & 0.05 \\
Sensation of anorectal blockage & 0.04 & & -0.03 \\
\hline
\end{tabular}

${ }^{\mathrm{a}} P<0.01$.

GC, geometric center; BSFS, Bristol stool form scale; BMs, bowel movements.

44.4\% positive predictive value, and $91.7 \%$ negative predictive value (Table 3 ). A combined stool form (mean 5-day BSFS $\leq$ 3 ) and frequency ( $\leq 2 \mathrm{BMs}$ in 5 days) provided $50.0 \%$ sensitivity, $92.4 \%$ specificity, $59.1 \%$ positive predictive value, and $90.2 \%$ negative predictive value.

\section{Correlation of Stool Characteristics and with Geometric Center}

Both the mean 5-day BSFS and stool frequencies moderately and positively correlated with GC on day 1,3 , and 5 , meaning that the looser stool and higher frequency of BMs correlated with faster colonic motility (Table 4). All constipation symptoms demonstrated non-significant correlation with GC.

\section{Subgroup Analysis}

Our patients were divided into 2 subgroups: IBS and non-IBS. In IBS patients, stool form and frequency were not associated with delayed CTT and the correlation between stool form, frequency, and colonic motility were either weaker or not significant. Whereas, the association and the correlation of stool form, frequency, and colonic motility remain significant in non-IBS patients (Supplementary Tables 1 and 2).

\section{Discussion}

Clinical information easily obtained from constipated patients during outpatient visits including stool characteristics (stool form and frequency) and other gastrointestinal symptoms might guide doctors' treatment strategies. However, different diet and bowel habits in different populations limit its application in general. ${ }^{33}$ Available studies on the association of stool characteristics and CTT were from the West. To the best of our knowledge, this is the first study to determine the association between stool characteristics using BSFS, stool frequency, and colonic transit in Asian constipated individuals.

Most previous studies investigated the association of stool form and colonic transit in healthy and IBS individuals. ${ }^{19-24,34}$ Only a study from Saad et $\mathrm{al}^{26}$ investigated this association in constipated adults by using ROM to define delayed CTT. They showed that the mean 5-day BSFS of less than or equal to 2 was optimal for predicting delayed CTT with $80.0 \%$ sensitivity and $69.0 \%$ specificity. Our study was also done in well-defined chronic constipated individuals and showed significant correlation of stool form and CTT, which supports the finding from Saad et al. ${ }^{26}$ However, our study showed that the optimal value of mean 5-day BSFS for predicting delayed CTT was less than or equal to 3 providing $68.0 \%$ sensitivity, $69.7 \%$ specificity, and $69.4 \%$ accuracy. This finding suggests that, in Eastern constipation patients, not only BSFS 1 and 2 but also BSFS 3 was associated with delayed colonic transit. This difference might be attributed to different ethnic groups, dietary habits, and quantity of fiber intake between the Asian and the Western patients. ${ }^{33}$ Moreover, our findings also supported the previous consensus from the Asian Neurogastroenterology and Motility Association that used BSFS 1 to 3 to characterize IBS with constipation, ${ }^{29}$ which differed from the West (BSFS 1 to 2 ). ${ }^{28}$ Furthermore, we assessed the correlation of BSFS and GC, after which we found only moderate correlation. For practical purposes, the mean 5-day BSFS can discriminate delayed CTT from normal CTT qualitatively, but the BSFS may not be used for grading the severity of delayed colonic transit.

The correlation of stool frequency and colonic transit in constipation, IBS, and healthy adults have shown contradictory results. ${ }^{19-21,23,24}$ Glia et $\mathrm{al}^{34}$ showed that less than 2 BMs per week was the independent predictor for slow-transit constipation, whereas 
Saad et $\mathrm{al}^{26}$ showed no correlation when measured by wireless motility capsule and ROM. Our study demonstrated that stool frequency is an independent predictor for delayed CTT and it showed moderate correlation with GC. Stool frequency also had a fair predictive ability for delayed CTT with the optimal stool frequency of less than or equal to $2 \mathrm{BMs}$ per 5 days providing $64.0 \%$ sensitivity, $83.1 \%$ specificity, and $84.0 \%$ accuracy.

Besides stool characteristics, physicians frequently assess gastrointestinal symptoms during an ambulatory visit. So far, only a few studies evaluated the association between symptoms and colonic motility and have reported different results. ${ }^{23,35}$ There was a large cohort study of IBS patients that investigated the association of three gastrointestinal symptoms (abdominal pain, bloating, and flatulence) with colonic motility, showing only weak correlation of abdominal pain with $\mathrm{CTT}{ }^{23}$ Whereas the other cohort found significantly higher severity of urgency and bloating in delayed CTT compared with normal CTT. ${ }^{35}$ All 5 constipation symptoms (straining, hard stools, incomplete evacuation, manual maneuver to facilitate defecation, and sensation of anorectal blockage) were not good markers for discriminating delayed CTT from normal CTT individuals as shown in our study.

Our study found weaker correlation and non-significant association between stool form, frequency, and colonic motility in IBS patients, whereas those findings remain significant in non-IBS patients. There are a few plausible explanations on these findings. First, in IBS patients, stool consistency varies greatly within each individual, and bowel habits were also found to change overtime, ${ }^{36,37}$ thus the reliability of the measurements of stool form and frequency in IBS patients come into question given this day-to-day variation. Second, colonic absorption and secretion may be different in patients with IBS compared to those without IBS. ${ }^{38}$

Our study has limitations that should be acknowledged. First, we assessed colonic motility in patients with constipation, therefore the correlation of BSFS and rapid colonic transit could not be demonstrated. Second, psychological stress was found to enhance colonic motor activity. ${ }^{39,40}$ However, psychological stressors were not assessed in our study. Caution should be noted in interpreting our study findings. According to the American Gastroenterological Association medical position statement on constipation, ${ }^{41}$ defecation disorders should be ruled out prior to performing a colonic transit study to determine delayed colonic motility. With the primary aim of determining office-based surrogate marker for delayed colonic motility, all constipated patients were included regardless of the final diagnosis. With our cut-offs of stool form and frequency, they could predict delayed colonic motility, which could be either delayed co- lonic motility alone or delayed colonic motility-defecation disorder overlapping diseases.

In summary, moderate correlation exists between stool form, frequency, and colonic motility. Stool form and frequency were independently associated with delayed colonic transit. We suggest that both stool form and frequency can be used as a simple office-based surrogate for colonic motility. A combined stool form (mean 5-day BSFS $\leq 3$ ) and frequency ( $\leq 2 \mathrm{BMs}$ in 5 days) could provide $50.0 \%$ sensitivity, $92.4 \%$ specificity, $59.1 \%$ positive predictive value, and $90.2 \%$ negative predictive value. An mean 5-day BSFS of less than or equal to 3 or stool frequency of less than or equal to $2 \mathrm{BMs}$ per 5 days could be used as surrogate markers for predicting delayed colonic motility in chronic constipation patients in Asia.

\section{Supplementary Materials}

Note: To access the supplementary tables mentioned in this article, visit the online version of Journal of Neurogastroenterology and Motility at http://www.jnmjournal.org/, and at https://doi. org/10.5056/jnm17022.

Acknowledgements: We thank Mrs Amporn Tanawatsuggasere and Ms Sukuma Suksri, Gastrointestinal Motility Research Unit, Division of Gastroenterology, Department of Medicine, Faculty of Medicine, Chulalongkorn University for their assistance on data acquisition.

Financial support: This study was supported in part by the Ratchadapiseksompotch Endowment Fund (GI Motility Research Unit grant).

\section{Conflicts of interest: None.}

Author contributions: Veeravich Jaruvongvanich contributed to the acquisition, analysis, and interpretation of the data, and drafted the article; and Tanisa Patcharatrakul and Sutep Gonlachanvit designed the study, recruited patients, drafted the article, and critically revised the manuscript for important intellectual content.

\section{References}

1. Suares NC, Ford AC. Prevalence of, and risk factors for, chronic idiopathic constipation in the community: systematic review and metaanalysis. Am J Gastroenterol 2011;106:1582-1591.

2. Shaheen NJ, Hansen RA, Morgan DR, et al. The burden of gastrointestinal and liver diseases, 2006. Am J Gastroenterol 2006;101:2128-2138. 
3. Shah ND, Chitkara DK, Locke GR, Meek PD, Talley NJ. Ambulatory care for constipation in the United States, 1993-2004. Am J Gastroenterol 2008;103:1746-1753.

4. Nyrop KA, Palsson OS, Levy RL, et al. Costs of health care for irritable bowel syndrome, chronic constipation, functional diarrhoea and functional abdominal pain. Aliment Pharmacol Ther 2007;26:237-248.

5. Wald A, Scarpignato C, Kamm MA, et al. The burden of constipation on quality of life: results of a multinational survey. Aliment Pharmacol Ther 2007;26:227-236.

6. Sun SX, Dibonaventura M, Purayidathil FW, Wagner JS, Dabbous O, Mody R. Impact of chronic constipation on health-related quality of life, work productivity, and healthcare resource use: an analysis of the National Health and Wellness Survey. Dig Dis Sci 2011;56:2688-2695.

7. Bharucha AE, Pemberton JH, Locke GR 3rd. American Gastroenterological Association technical review on constipation. Gastroenterology 2013;144:218-238.

8. Rao SS, Benninga MA, Bharucha AE, Chiarioni G, Di Lorenzo C, Whitehead WE. ANMS-ESNM position paper and consensus guidelines on biofeedback therapy for anorectal disorders. Neurogastroenterol Motil 2015;27:594-609.

9. Bove A, Bellini M, Battaglia E, et al. Consensus statement AIGO/ SICCR diagnosis and treatment of chronic constipation and obstructed defecation (part II: treatment). World J Gastroenterol 2012;18:49945013.

10. Gwee KA, Ghoshal UC, Gonlachanvit S, et al. Primary care management of chronic constipation in Asia: the ANMA chronic constipation tool. J Neurogastroenterol Motil 2013;19:149-160.

11. Lee YY. What's new in the toolbox for constipation and fecal incontinence? Front Med (Lausanne) 2014;1:5

12. Southwell BR, Clarke MC, Sutcliffe J, Hutson JM. Colonic transit studies: normal values for adults and children with comparison of radiological and scintigraphic methods. Pediatr Surg Int 2009;25:559-572.

13. Meir R, Beglinger C, Dederding JP, et al. [Age- and sex-specific standard values of colonic transit time in healthy subjects.] Schweiz Med Wochenschr 1992;122:940-943. [German]

14. Sadik R, Abrahamsson H, Stotzer PO. Gender differences in gut transit shown with a newly developed radiological procedure. Scand J Gastroenterol 2003;38:36-42.

15. Nabar AA, Bhatia SJ, Abraham P, Ravi P, Mistry FP. Total and segmental colonic transit time in non ulcer dyspepsia. Indian J Gastroenterol 1995;14:131-133.

16. Song BK, Cho KO, Jo Y, Oh JW, Kim YS. Colon transit time according to physical activity level in adults. J Neurogastroenterol Motil 2012;18:64-69.

17. Chan YK, Kwan AC, Yuen H, et al. Normal colon transit time in healthy Chinese adults in Hong Kong. J Neurogastroenterol Motil 2004;19:1270-1275.

18. Ghoshal UC, Sengar V, Srivastava D. Colonic transit study technique and interpretation: can these be uniform globally in different populations with non-uniform colon transit time? J Neurogastroenterol Motil 2012;18:227-228.

19. Lewis SJ, Heaton KW. Stool form scale as a useful guide to intestinal transit time. Scand J Gastroenterol 1997;32:920-924.

20. O'Donnell LJ, Virjee J, Heaton KW. Detection of pseudodiarrhoea by simple clinical assessment of intestinal transit rate. BMJ 1990;300:439440

21. Heaton KW, O’Donnell LJ. An office guide to whole-gut transit time. Patients' recollection of their stool form. J Clin Gastroenterol 1994;19:2830.

22. Degen LP, Phillips SF. How well does stool form reflect colonic transit? Gut 1996;39:109-113.

23. Törnblom H, Van Oudenhove L, Sadik R, Abrahamsson H, Tack J, Simrén M. Colonic transit time and IBS symptoms: what's the link? Am J Gastroenterol 2012;107:754-760.

24. Shim L, Talley NJ, Boyce P, Tennant C, Jones M, Kellow JE. Stool characteristics and colonic transit in irritable bowel syndrome: evaluation at two time points. SScand J Gastroenterol 2013;48:295-301.

25. Bouchoucha M, Devroede G, Dorval E, Faye A, Arhan P, Arsac M. Different segmental transit times in patients with irritable bowel syndrome and "normal" colonic transit time: is there a correlation with symptoms? Tech Coloproctol 2006;10:287-296.

26. Saad RJ, Rao SS, Koch KL, et al. Do stool form and frequency correlate with whole-gut and colonic transit? Results from a multicenter study in constipated individuals and healthy controls. Am J Gastroenterol 2010;105:403-411.

27. Russo M, Martinelli M, Sciorio E, et al. Stool consistency, but not frequency, correlates with total gastrointestinal transit time in children. J Pediatr 2013;162:1188-1192.

28. Longstreth GF, Thompson WG, Chey WD, Houghton LA, Mearin F, Spiller RC. Functional bowel disorders. Gastroenterology 2006;130:1480-1491.

29. Gwee KA, Bak YT, Ghoshal UC, et al. Asian consensus on irritable bowel syndrome. J Gastroenterol Hepatol 2010;25:1189-1205.

30. Gonlachanvit S, Patcharatrakul T. Causes of idiopathic constipation in Thai patients: associations between the causes and constipation symptoms as defined in the Rome II criteria. J Med Assoc Thai 2004;87(suppl 2):S22-S28.

31. Arhan P, Devroede G, Jehannin B, et al. Segmental colonic transit time. Dis Colon Rectum 1981;24:625-629.

32. Evans RC, Kamm MA, Hinton JM, Lennard-Jones JE. The normal range and a simple diagram for recording whole gut transit time. Int $\mathrm{J}$ Colorectal Dis 1992;7:15-17.

33. Panigrahi MK, Kar SK, Singh SP, Ghoshal UC. Defecation frequency and stool form in a coastal eastern Indian population. J Neurogastroenterol Motil 2013;19:374-380.

34. Glia A, Lindberg G, Nilsson LH, Mihocsa L, Akerlund JE. Clinical value of symptom assessment in patients with constipation. Dis Colon Rectum 1999;42:1401-1408; discussion 1408-1410.

35. Sadik R, Björnsson E, Simrén M. The relationship between symptoms, body mass index, gastrointestinal transit and stool frequency in patients with irritable bowel syndrome. Eur J Gastroenterol Hepatol 2010;22:102-108.

36. Garrigues V, Mearin F, Badia X, et al. Change over time of bowel habit in irritable bowel syndrome: a prospective, observational, 1-year follow- 
up study (RITMO study). Aliment Pharmacol Ther 2007;25:323-332.

37. Palsson OS, Baggish JS, Turner MJ, Whitehead WE. IBS patients show frequent fluctuations between loose/watery and hard/lumpy stools: implications for treatment. Am J Gastroenterol 2012;107:286-295.

38. Hayes PA, Fraher MH, Quigley EM. Irritable bowel syndrome: the role of food in pathogenesis and management. Gastroenterol Hepatol (N Y) 2014;10:164-174.

39. Rao SS, Hatfield RA, Suls JM, Chamberlain MJ. Psychological and physical stress induce differential effects on human colonic motility. Am J
Gastroenterol 1998;93:985-990.

40. Mönnikes H, Tebbe JJ, Hildebrandt M, et al. Role of stress in functional gastrointestinal disorders. Evidence for stress-induced alterations in gastrointestinal motility and sensitivity. Dig Dis 2001;19:201-211.

41. American Gastroenterological Association, Bharucha AE, Dorn SD, Lembo A, Pressman A. American Gastroenterological Association medical position statement on constipation. Gastroenterology 2013;144:211217. 